\title{
Diclofenac vs. Placebo in a Randomized Double Blind Controlled Trial, in Post ERCP Pancreatitis
}

\author{
Yasser Abu-Safieh", Raed Altiti, Mohammad Lobadeh \\ Specialized Arab Hospital, affiliated with school of Medicine, An Najah University, Nablus, Palestine \\ *Corresponding author: yaserasaf@hotmail.com
}

Received January 12, 2014; Revised February 28, 2014; Accepted March 02, 2014

\begin{abstract}
Background and Study Aim: In several studies non-steroidal anti inflammatory drugs (NSAIDs) showed reduction of post (ERCP) pancreatitis incidence and severity. Our aim is to study the effect of NSAIDs in reducing post ERCP pancreatitis (PEP). Patients and Methods: A double blind placebo controlled study was conducted, patients who underwent ERCP in Specialized Arab Hospital (SAH), collected over one year, from June 2012 to June 2013 . Patients were randomized by an endoscopy nurse to receive IM Diclofenac $75 \mathrm{mg}$, or IM isotonic saline $3 \mathrm{ml}$ as placebo. 12 hours after completing the procedure all patients were evaluated for abdominal pain and serum amylase. Results: The total number of patients was 199 patients, 17 patients were excluded, 182 patients completed the study, diclofenac group (89), placebo (93), the two groups were comparable for the following: age, sex, ERCP finding, pancreatic duct cannulation, failure of common bile duct (CBD) cannulation, number of pancreatic duct cannulation, ERCP time, sphincterotomy, and stenting. The overall incidence of pancreatitis was $(18 / 182) 10 \%$, (6/89) $6.9 \%$ for the diclofenac group and (12/93) $12.9 \%$ for the placebo group. There was no significant difference in the incidence of pancreatitis between the two groups; the P value was 0.164 . In all the cases in which pancreatitis occurs, it was mild or moderate; there was no severe pancreatitis among the two groups. But in subgroup analysis the frequency of pancreatitis in patients with multiple pancreatic duct cannulation was significantly lower in the diclofenac group than in control group with p value $=0.021$. Conclusion: Intramuscular diclofenac does not lower PEP rate or severity. But it significantly decreased PEP in patients with multiple pancreatic duct cannulations.
\end{abstract}

\section{Keywords: diclofenac, ERCP, pancreatitis}

Cite This Article: Yasser Abu-Safieh, Raed Altiti, and Mohammad Lobadeh, "Diclofenac vs. Placebo in a Randomized Double Blind Controlled Trial, in Post ERCP Pancreatitis." American Journal of Clinical Medicine Research, vol. 2, no. 2 (2014): 43-46. doi: 10.12691/ajcmr-2-2-1.

\section{Introduction}

TAcute pancreatitis is the most common complication of ERCP, reaching an incidence of $4 \%$ in low risk patients, and $40 \%$ high risk patients. The majority of patients suffer from mild pancreatitis, while severe pancreatitis occurs in $0.3 \%-0.6 \%[1]$.

PEP is defined as acute pancreatitis that has occurred de novo following ERCP and, according to the consensus guidelines proposed by Cotton et al. in 1991, is the occurrence of new abdominal pain associated with at least a threefold increase in serum amylase concentration occurring 24 hours after an ERCP. The pain should be severe enough to cause admission of the patient to the hospital or extend an admitted patient's hospitalization [2].

The severity of PEP was stratified to mild, moderate and severe. This grading depends on the length of hospitalization. A mild PEP was defined as the need for hospitalization up to 3 days, the moderate one was defined as the need for hospitalization for 4-10 days, and the severe PEP was defined as more than 10 days with a significant complication. The Atlanta classification can be used for grading the severity of PEP; this depends on the presence or absence of local (recorded by CT) or systemic complications, without giving importance to the duration of the hospital stay [3].

Identifying cases which have relatively higher risk of developing PEP is very important, so that preventive measures such as pancreatic stenting or pharmacological prophylaxis can be performed [4]. Risk factors can be divided into patient, operation, and operator related risk factors. Patient-related risk factors include: younger age, indication of suspected sphincter of Oddi dysfunction, history of previous PEP, and absence of elevated serum bilirubin [5]. Females may have increased risk [6]. Operation related risk factors include: ampullary balloon dilation, precut access sphincterotomy, endoscopic sphincterotomy (ES), sphincter of Oddi manometry, distal common bile duct diameters of $1 \mathrm{~cm}$, presence of a pancreatic stricture, papillectomy, and procedures not involving stone removal [7]. Cannulation of the papilla, especially in moderate and difficult cases, is associated with increased risk of PEP. Procedures involving multiple cannulation $(>3)$ or failure attempts of cannulation, multiple pancreatic injections $(>2)$, and prolonged cannulation time (>10 min) are associated with increasing 
the risk of PEP [7]. Operator experience also contributes to increasing the risk of PEP [7].

The mechanism of action of NSAIDs includes the inhibition of phospholipase A2 which has an early role in inducing the inflammatory cascade in acute pancreatitis [8]. Nowadays, there are high hopes regarding NSAIDs because of their low cost and safety. At the same time, it has also been shown to have beneficial effects in experimental acute pancreatitis [9].

The aim of this study was to evaluate the efficacy of intramuscular (IM) diclofenac in prevention of pancreatitis or in decreasing the severity of pancreatitis in all eligible patients who underwent ERCP in SAH.

\section{Patients and Methods}

The study described in this report was approved by Institutional Research Board (IRB). All patients signed informed consents for the procedure, and the participation in the study. Between June 2012 and June 2013, 199 patients fulfilled the inclusion criteria, 182 of whom were included in the final analysis (Figure 1). Patients were excluded from study participation if they had a contraindication for diclofenac, including patients with recently diagnosed peptic ulcer disease, renal failure, those who developed acute pancreatitis during the two weeks before ERCP, those with a history of chronic pancreatitis, and those who did not agree to participate in the study (Table 4). Entry to the study was restricted to patients advised to have endoscopic retrograde cholangiography. A prospective, placebo-controlled trial was conducted in 182 patients who underwent ERCP. Preoperative, the patients received $75 \mathrm{mg}$ IM diclofenac or IM normal saline as placebo. At the end of each procedure, the researchers recorded the details of the maneuvers performed, including the total time of the procedure, the number of attempts at cannulation, the number of pancreatic duct cannulation, the final diagnosis by ERCP, and whether a sphincterotomy, a needle-knife papillotomy, or stent placement were performed. Serum amylase was determined 12 hours after ERCP. If the 12-h serum amylase level was $>3$ times the upper normal limit and the patient exhibited pain or nausea and vomiting, then the patient had pancreatitis. Acute pancreatitis was defined as serum amylase $>3$ times the upper limit of normal and associated with epigastric pain, back pain, and epigastric tenderness.

\section{Statistical Analysis}

Randomization was done by the GI nurse, concealed envelop:

Data were summarized by descriptive statistics. The Chi square was used to compare categorical patient data. The Student's t test was used to compare continuous variables. Two-tailed $\mathrm{P}<0.05$ was considered to indicate significance.

\section{Results}

A total of 199 pts, 182 patients were eligible for the study. 89 patients received $75 \mathrm{mg}$ diclofenac (diclofenac group), and 93 received IM normal saline (control group). No patients discontinued the study medication because of adverse effects. Overall, the baseline characteristics were consistent across all treatment groups (Table 1). The mean ages of patients in the diclofenac and control groups were $51.90 \pm 19.56$ years and $57.71 \pm 19.39$ years, respectively. There were 53 women in the diclofenac group and 58 in the control group. Similarly, there were no statistically significant differences between the groups considering the procedures, and factors that might increase the risk of pancreatitis, including single or repeated pancreatic duct injection, younger age, female sex and precut endoscopic sphincterotomy (Table 1). There was no difference between the two groups. The most frequent diagnosis by ERCP was bile duct stone in the diclofenac (37.1\%) and control (49.5\%) group. Pancreatitis occurred in 18/182 patients $(10 \%)$, six of whom $(6.7 \%)$ belonged to the diclofenac group and twelve (12.9\%) belonged to the control group (Table 2), there was no significant difference between the two groups. But in subgroup analysis the frequency of pancreatitis in patients with multiple pancreatic duct cannulation it was significantly lower in the diclofenac group than in control group with $\mathrm{p}$ value $=0.021$ (Table 4$)$.

Table 1. The characteristics of patients in diclofenac and control group

\begin{tabular}{|c|c|c|c|}
\hline Variables & $\begin{array}{l}\text { Diclofenac } \\
\text { group }\end{array}$ & $\begin{array}{l}\text { Control } \\
\text { group }\end{array}$ & $\begin{array}{c}\mathrm{P} \\
\text { value }\end{array}$ \\
\hline Age (years) $(*)$ & & & \multirow{3}{*}{0.07} \\
\hline$>=60$ & $34 / 89$ & $48 / 93$ & \\
\hline$<60$ & 55/89 & $45 / 93$ & \\
\hline Male/female ratio $\left(^{*}\right)$ & $36 / 53$ & $35 / 58$ & 0.69 \\
\hline Sphincterotomy (*) & & & \multirow{3}{*}{0.42} \\
\hline Yes & $72 / 89$ & $72 / 93$ & \\
\hline No & $17 / 89$ & $21 / 93$ & \\
\hline Needle knife fistulotomy $(*)$ & & & \multirow{3}{*}{.326} \\
\hline Yes & $5 / 89$ & 3/93 & \\
\hline No & $84 / 89$ & $90 / 93$ & \\
\hline Diagnosis by ERCP $(*)$ & & & \multirow{7}{*}{0.27} \\
\hline Dilation with stone & $33 / 89$ & $46 / 93$ & \\
\hline Dilation without stone & $24 / 89$ & $22 / 93$ & \\
\hline Malignancy & $16 / 89$ & $8 / 93$ & \\
\hline Ampullary stenosis & $3 / 89$ & $4 / 93$ & \\
\hline Normal & $7 / 89$ & $4 / 93$ & \\
\hline Other causes & $6 / 89$ & 9/93 & \\
\hline Pancreatic duct cannulation $(*)$ & & & 0.95 \\
\hline Yes & $36 / 89$ & 38/93 & \\
\hline No & $53 / 89$ & $55 / 93$ & \\
\hline $\begin{array}{c}\text { Failure of common bile duct } \\
\text { cannulation }(*)\end{array}$ & & & 0.69 \\
\hline Yes & $6 / 89$ & $5 / 93$ & \\
\hline No & $83 / 89$ & $88 / 93$ & \\
\hline $\begin{array}{l}\text { Number of pancreatic duct } \\
\text { cannulation }(*)\end{array}$ & & & 0.10 \\
\hline$<3$ & $81 / 89$ & 90/93 & \\
\hline$>=3$ & $8 / 89$ & $3 / 93$ & \\
\hline \multicolumn{3}{|l|}{ Stent $(*)$} & \multirow{3}{*}{0.58} \\
\hline Yes & $22 / 89$ & $25 / 93$ & \\
\hline No & $67 / 89$ & $68 / 93$ & \\
\hline ERCP time $(*)$ & & & \multirow{3}{*}{0.11} \\
\hline$<25 \min$ & $65 / 89$ & $77 / 93$ & \\
\hline$>=25 \min$ & $24 / 89$ & $16 / 93$ & \\
\hline
\end{tabular}


Table 2. the incidence and severity of post ERCP pancreatitis

\begin{tabular}{|c|c|c|c|}
\hline Variables & Diclofenac & Placebo & P value \\
\cline { 1 - 3 } Post ERCP pancreatitis $\left(^{*}\right)$ & & & \multirow{2}{*}{0.164} \\
\cline { 1 - 3 } Yes & $6 / 89$ & $12 / 93$ & \\
\cline { 1 - 3 } No & $83 / 89$ & $81 / 93$ & \\
\cline { 1 - 3 } Severity of pancreatitis $\left(^{*}\right)$ & & & \multirow{2}{*}{0.289} \\
\cline { 1 - 3 } Mild & $3 / 6$ & $9 / 12$ & \\
\hline Moderate & $3 / 6$ & $3 / 12$ & \\
\hline
\end{tabular}

Twelve hours after the endoscopy, the median of serum amylase level was $100 \mathrm{IU} / \mathrm{L}$ in the diclofenac group and $100 \mathrm{IU} / \mathrm{L}$ in the control group. (Table 3). There was no statistical difference between the two groups in amylase level $(\mathrm{P}>0.05)$.
Table 3. the incidence of PEP in subgroups analysis

\begin{tabular}{l}
\begin{tabular}{|c|c|c|c|}
\hline Variables & Diclofenac & Placebo & P value \\
\hline Age (years) & & & \\
\hline$>=60$ & & & \\
\hline$<60$ & $1 / 34$ & $4 / 48$ & 0.315 \\
\hline Sex & $5 / 55$ & $8 / 45$ & 0.199 \\
\hline male & & & \\
\hline female & $2 / 36$ & $5 / 35$ & 0.217 \\
\hline Pancreatic duct cannulation** & $4 / 53$ & $7 / 58$ & 0.426 \\
\hline$>$ CHI square was used, **Fisher's Exact Test was use & \\
\hline
\end{tabular} \\
\hline
\end{tabular}

Table 4. the causes of exclusion of the 17 patients

\begin{tabular}{|c|c|}
\hline 1. Failure to reach the ampulla due to: & Number of patients \\
\hline A. Pyloric stenosis & 3 \\
\hline B. Ampullary tumor & 3 \\
\hline C. Diverticula & 1 \\
\hline 2. ERCP done recently & 4 \\
\hline 3. Stent replacement & 3 \\
\hline 4.CHF & 2 \\
\hline 5. Asthma & 1 \\
\hline
\end{tabular}

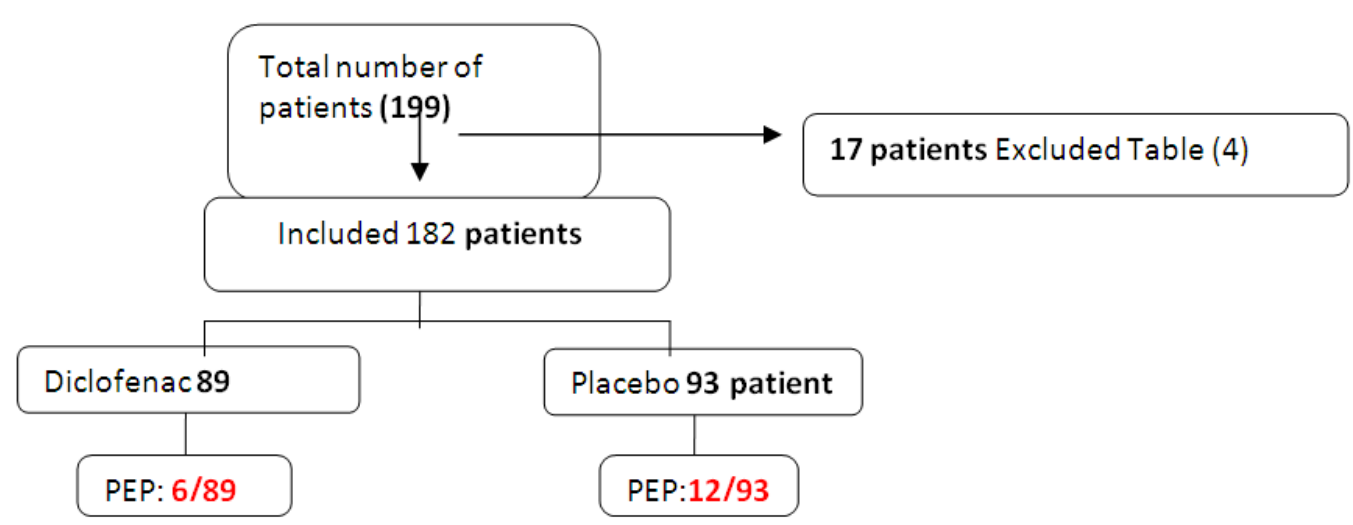

Figure 1 (Flow Diagram). Showed the flow of patients including the total number of patients and those included and completed the study, the 2 groups, and those with the diagnosis of post ERCP pancreatitis (PEP)

\section{Discussion}

Although post-ERCP pancreatitis (PEP) is reported to occur in $1-40 \%$ of cases, in prospective studies, it is reported to occur in $5-7 \%$ [10]. The only sure way to prevent post ERCP pancreatitis is to avoid doing it. Therefore, careful consideration should be given to the indications and the risk/benefit ratio before ERCP is performed. Once the decision to pursue ERCP is made, the procedure should be carried out with meticulous care by an experienced endoscopist, and with a minimum of pancreatic duct, cannulation and opacification [11]. Despite numerous studies on pharmacological prophylaxis nothing is proven in preventing PEP. Various pharmacological agents (such as nifedipine, glucagon, calcitonin, lidocaine, nitroglycerine, antibiotics, steroids, allopurinol, interleukin-10, and heparin) have been tried, but have met with disappointing results in preventing pancreatitis in randomized controlled trials [9]. The rationale for using an NSAID is attractive, because these drugs may prevent pancreatitis by inhibiting prostaglandin synthesis and interrupting the inflammatory cascade of pancreatitis; the NSAID could therefore be given not only before the ERCP procedure, to patients with well-known risk factors for post-ERCP pancreatitis - for example, antisecretory and anti protease agents - but also immediately after the procedure, in standard-risk cases, when there are procedure-related risk factors (multiple contrast injection of the pancreatic duct, difficult cannulation, pre-cut, pancreatic sphincterotomy, balloon dilation of the sphincter of Oddi) [12]. NSAIDs are inexpensive and easily administered and have a favorable risk profile when given as a single dose, making them an attractive option in the prevention of post-ERCP pancreatitis [13]. Former studies evaluating the protective effects of single-dose rectal indomethacin or diclofenac in PEP have been conducted, and some suggest benefit.

The first clinical trial assessing the efficacy of a rectally administered NSAID for PEP prevention was reported in 2003 [14], patient number was 220 patients, 110 randomly received rectal diclofenac and the others received placebo, in that study the pancreatitis occurred in $6.4 \%$ of patients in NSAID group compared to $15.5 \%$ in the control group; there was a significant difference between the two groups $\mathrm{p}$ value $=0.049$.

In 2007, a clinical trial [15] was conducted, 100 patients were included, 50 patients randomly received 100 mg rectally and the other 50 patients received placebo, in this research researchers focused only on those who underwent pancreatic duct injection, the overall incidence of pancreatitis was $15 \%$, the incidence of pancreatitis was $26 \%(13 / 50), 4 \%(2 / 50)$ in placebo, diclofenac group respectively, this difference was statically significant with $\mathrm{p}$ value $<0.01$. Another study [16] was conducted, in which 490 patient participated, 245 patients randomly received $100 \mathrm{mg}$ rectally and the other 245 patients received placebo, the overall incidence of pancreatitis was $5 \%$, the incidence of pancreatitis was $6.8 \%$ (15/245), 3.2\% 
(7/245) in placebo and diclofenac groups respectively, this difference was statically not significant with $\mathrm{p}$ value $=$ 0.06. In another study [17], 150 patients were included, 75 patients randomly received $100 \mathrm{mg}$ rectally and the other 75 patients received placebo, the overall incidence of pancreatitis was $10.7 \%$, the incidence of pancreatitis was $16 \%(12 / 75)$, $5.3 \%(4 / 75)$ in placebo and diclofenac groups respectively, this difference was statically significant with $\mathrm{p}$ value $=0.034$. Another study [18] was conducted, 223 patients were included, 111 patients randomly received oral diclofenac and the other 112 patients received placebo, the incidence of pancreatitis was of pancreatitis was (17/112), 5.3\% (17/111) in placebo and diclofenac groups respectively, this difference was not statically significant. Another study [19] was conducted, 117 patient were included, 61 patient randomly received $100 \mathrm{mg}$ rectally and the other 56 patients received placebo, the overall incidence of pancreatitis was $10.7 \%$, the incidence of pancreatitis was $6.8 \%(8 / 56)$, $2.5 \%(3 / 61)$ in placebo, diclofenac group respectively, this difference was not statically significant.

In 2012, there was a well-designed meta-analysis [20], in this meta-analysis, prophylactic NSAIDs were effective in preventing PEP. Widespread prophylactic administration of these agents may significantly reduce the incidence of PEP, resulting in major clinical and economic benefits. Given current skepticism regarding the efficacy of any prophylactic medication for ERCP, additional multicentre studies are needed for confirmation prior to widespread adoption of this strategy [20] currently there is new research was conducted between Aug 2006 and April 2008 [9], 80 patients were included, 40 patients randomly received $75 \mathrm{mg}$ IM injection and fluid replacement and the other 40 patients received placebo, the overall incidence of pancreatitis was $12.5 \%$, the incidence of pancreatitis was $17.5 \%$ (7/40), $7.5 \%$ (3/40) in placebo and diclofenac groups respectively, this difference was statically not significant. But in subgroup analysis the frequency of pancreatitis in patients with sphincter of Oddi dysfunction was significantly lower in the diclofenac group than in control group with $\mathrm{p}$ value $=0.047$. Comparing our results with what is found in literature, high risk patient with multiple PD cannulation has significant difference $(\mathrm{P}=0.021)$ between diclofenac and placebo group, upon subgroup analysis.

In conclusion, our study showed that IM diclofenac did not prevent the occurrence of pancreatitis, in the study group. But we noticed a significant difference in repeated PD cannulation; diclofenac prevents PEP in this sub group.

\section{Conflict of Interests}

No conflict of interest and nothing to disclose.

\section{References}

[1] Lieb II JG, Draganov PV. Early successes and late failures in the prevention of post endoscopic retrograde cholangiopancreatography pancreatitis. World J Gastroenterol 2007 July 14; 13 (26): 3567-3574.

[2] Freeman ML, Nelson DB, Sherman S, Haber GB, Herman ME, Dorsher PJ, Moore JP, Fennerty MB, Ryan ME, Shaw MJ, Lande JD, Pheley AM. Complications of endoscopic biliary sphincterotomy. N Engl J Med 1996; 335: 909-918.
[3] Cheon YK, Cho KB, Watkins JL, McHenry L, Fogel EL,Sherman S, Lehman GA. Frequency and severity of post- ERCP pancreatitis correlated with extent of pancreatic ductalopacification. Gastrointest Endosc 2007; 65: 385-393.

[4] Freeman ML, DiSario JA, Nelson DB, Fennerty MB, Lee JG,Bjorkman DJ, Overby CS, Aas J, Ryan ME, Bochna GS, Shaw MJ, Snady HW, Erickson RV, Moore JP, Roel JP. Risk factors. for post-ERCP pancreatitis: a prospective, multicenter study.Gastrointest Endosc 2001; 54: 425-434.

[5] Rabenstein T, Framke B, Martus P, et al. Method related riskfactors for complications of endoscopic sphincterotomy. Aprospective study (abstract). Gastrointest Endosc 1999; 49: AB

[6] Cheng CL, Sherman S, Watkins JL, Barnett J, Freeman M, Geenen J, Ryan M, Parker H, Frakes JT, Fogel EL, Silverman WB, Dua KS, Aliperti G, Yakshe P, Uzer M, Jones W, Goff J, LazzellPannell L, Rashdan A, Temkit M, Lehman GA. Risk factors for post-ERCP pancreatitis: a prospective multicenter study. Am J Gastroenterol. 2006 Jan; 101 (1): 139-47.

[7] González-Ojeda A 1, Dávalos-Cobian C 2, Andalón-Dueñas E 1 , Chávez-Tostado M 1, Espinosa-Partida A 1, Fuentes-Orozco C 1. Endoscopic Retrograde Cholangiopancreatography-Related Acute Pancreatitis - Identification, Prophylaxis and Treatment.

[8] Döbrönte Z. Endoscopic Retrograde Cholangiopancreatography (ERCP) Related Acute Pancreatitis.

[9] Altug S, Ulku S, Halil D. Efficacy of intramuscular diclofenac and fluid replacement in prevention of post-ERCP pancreatitis. World J Gastroenterol 2009 August 28; 15 (32): 3999-4004 wjg@wjgnet.com World Journal of Gastroenterology ISSN 10079327.

[10] Ülkü S, Yücel Ü, Todd H. Prevention of post-ERCP pancreatitis. Turk J Gastroenterol 2011; 22 (5): 449-463.

[11] John G, Peter V. Early successes and late failures in the prevention of post endoscopic retrograde cholangiopancreatography. World J Gastroenterol 2007 July 14; 13 (26): 3567-3574.

[12] Pier T. Simple measures to prevent post-ERCP pancreatitis. Gut 2008; 57: 1197-1198.

[13] Elmunzer BJ, Scheiman JM, Lehman GA, Chak A, Mosler P, Higgins PD, Hayward RA, Romagnuolo J, Elta GH, Sherman S, Waljee AK, Repaka A, Atkinson MR, Cote GA, Kwon RS, McHenry L, Piraka CR, Wamsteker EJ, Watkins JL, KorsnesSJ, Schmidt SE, Turner SM, Nicholson S, Fogel EL. A randomized trial of rectal indomethacin to prevent post-ERCP pancreatitis. N Engl J Med 2012; 366: 1414-1422.

[14] Murray B, Carter R, Imrie C, Evans S, O’Suilleabhain C. Diclofenac reduces the incidence of acute pancreatitis after endoscopic retrograde cholangiopancreatography. Gastroenterology 2003; 124: 1786-1791.

[15] Khoshbaten M, Khorram H, Madad L, Ehsani Ardakani MJ, Farzin H, Zali MR. Role of diclofenac in reducing postendoscopic retrograde cholangiopancreatography pancreatitis. J Gastroenterol Hepatol. 2008; 23: e11-e16.

[16] Sotoudehmanesh R, Khatibian M, Kolahdoozan S, Ainechi S, Malboosbaf $R$, Nouraie $M$. Indomethacin may reduce the incidence and severity of acute pancreatitis after ERCP. Am J Gastroenterol. 2007; 102: 978-983.

[17] Montaño Loza A, Rodríguez Lomelí X, García Correa JE, Dávalos Cobián C, Cervantes Guevara G, Medrano Muñoz F, Fuentes Orozco C, González Ojeda A. [Effect of the administration of rectal indomethacin on amylase serum levels after endoscopic retrograde cholangiopancreatography, and its impact on the development of secondary pancreatitis episodes] Rev Esp Enferm Dig. 2007; 99: 330-336.

[18] Cheon YK, Cho KB, Watkins JL, et al. Efficacy of diclofenac in the prevention of post-ERCP pancreatitis in predominantly highrisk patients: a randomized double-blind prospective trial. Gastrointest Endosc 2007; 66: 1126-32.

[19] Montano Loza A, García Correa J, González Ojeda A, Fuentes Orozco C, Dá valos Cobián C, Rodríguez Lomelí X. Prevention of hyperamilasemia and pancreatitis after endoscopic retrograde cholangiopancreatography with rectal administration of indomethacin 27. Kapral C, Duller C, Wewalka F, Kerstan E, Vogel W, Schreiber F. Case volume and outcome of endoscopic retrograde cholangiopancreatography: results of a nationwide Austrian benchmarking project. Endoscopy. 2008; 40 (8): 625-30.

[20] Elmunzer BJ, Waljee AK, Elta GH, et al. A meta-analysis of rectal NSAIDs in the prevention of post-ERCP pancreatitis. Gut 2008; 57: $1262-7$. 